\title{
Perbandingan Efek Pemberian Bioinsektisida dan Ekstrak Kompos terhadap Produksi Padi Ratun dan Populasi Serangga Hama
}

\section{A Comparison between Effect of Bioinsecticide and Compost Extract on Ratooning Rice Production and Insect Pest Population}

\author{
Siti Herlinda ${ }^{1^{*}}$, Amarilisa Kusuma ${ }^{2}$, Suwandi $^{1}$, dan Andi Wijaya ${ }^{1}$ \\ ${ }^{1}$ Program Studi Agroekoteknologi, Fakultas Pertanian, Universitas Sriwijaya \\ Jl. Palembang Prabumulih Km 32, Indralaya Ogan Ilir, Sumatera Selatan 30662, Indonesia \\ ${ }^{2}$ Alumni Program Studi Agroekoteknologi, Faperta, Universitas Sriwijaya, Indralaya 30662
}

Diterima 22 April 2014/Disetujui 24 Oktober 2014

\begin{abstract}
The advantages of ratooning rice are to save water, cost production, labor, preparation time for planting and harvesting, but the ratooning productivity is still low. This research aimed to study the effect of the bioinsecticide and compost extract on ratooning rice production and insect populations. The ratooning rice was applied by bioinsecticide, compost extract, and combination of bioinsecticide and compost extract with dose $2 \mathrm{~L} \mathrm{ha} \mathrm{s}^{-1}$ per application, respectively. Data of agronomic variables were statistically analyzed using analysis of variance, whereas insect pest population data were analyzed using Chi Square test. The seedling height of ratoon applied by compost extract was the highest among treatments. The number of productive tillers per clumps and rice production on plot applied by compost extract were higher than the insecticide treatment. At the age of 17 day-ratooning rice, application bioinsecticide reduced the population of insect pests, such as Ciccadulina bipunctata, Recilia dorsalis, Nilaparvata lugens, and Nephotettix nigropictus. Thus, application of compost extract tended to improved the growth and production of the ratooning rice, while the bioinsecticide decreased the insect pest population.
\end{abstract}

Keywords: Beauveria bassiana, rice growth, production

\section{ABSTRAK}

Keunggulan budidaya padi ratun adalah penghematan air, biaya, tenaga kerja, waktu persiapan tanam dan panen, namun produktivitas padi ratun masih rendah. Penelitian ini bertujuan untuk mengkaji pengaruh aplikasi bioinsektisida dan ekstrak kompos terhadap produksi padi ratun dan populasi serangga hamanya. Padi ratun diberi perlakuan bioinsektisida, ekstrak kompos, dan kombinasi bioinsektisida dan ekstrak kompos yang dengan dosis masing-masing 2 L ha-1 per aplikasi. Data peubah agronomi dianalisis secara statistik menggunakan analisis ragam, sedangkan data populasi serangga hama dianalisis dengan menggunakan uji Khi Kuadrat. Aplikasi ekstrak kompos menghasilkan anakan padi ratun paling tinggi dibandingkan petak yang diberi aplikasi lainnya tetapi tidak berbeda nyata dibandingkan perlakuan kombinasi bioinsektisida dan ekstrak. Jumlah anakan produktif per rumpun dan produksi gabah kering giling menunjukkan hasil paling tinggi pada petak yang diberi aplikasi ekstrak kompos. Aplikasi bioinsektisida yang diaplikasikan pada saat padi ratun berumur 17 hari ternyata mampu menurunkan populasi serangga hama, Ciccadulina bipunctata, Recilia dorsalis, Nilaparvata lugens, dan Nephotettix nigropictus. Data ini memberi indikasi bahwa aplikasi ekstrak kompos meningkatkan pertumbuhan dan produksi padi, sedangkan bioinsektisida menurunkan populasi serangga hama padi ratun.

Kata kunci: Beauveria bassiana, pertumbuhan, produksi

\section{PENDAHULUAN}

Ratun (ratoon) atau singgang (Jawa) atau turiang (Sunda) adalah tanaman padi yang telah dipanen yang tumbuh kembali menghasilkan anakan baru dan selanjutnya dapat berproduksi kembali (Islam et al., 2008). Keunggulan

\footnotetext{
* Penulis untuk korespondensi. e-mail: sitiherlinda@unsri.ac.id
}

ratun, antara lain adalah waktu panen $40 \%$ lebih singkat, penghematan air sebanyak $60 \%$, penghematan input produksi sebanyak 38\% (Oad dan Cruz, 2002). Keunggulan lainnya adalah penghematan biaya, tenaga kerja, dan waktu persiapan tanam (Santos et al., 2003). Namun demikian, dari banyak keunggulan tersebut, produktivitas padi ratun cenderung masih rendah.

Upaya untuk meningkatkan produktivitas padi ratun telah banyak dilakukan penelitian, antara lain tentang 
penggunaan varietas dan galur tipe baru (Susilawati et al., 2010). Input produksi pada padi utama juga dapat mempengaruhi kebugaran ratunnya (Islam et al., 2008). Pemupukan $\mathrm{N}$ yang dikombinasikan dengan $\mathrm{P}$ atau $\mathrm{K}$ pada padi ratun juga dapat meningkatkan produktivitas padi ratunnya (Susilawati et al., 2012a) atau mengatur teknik budidaya, misalnya pengaturan tinggi pemotongan saat panen tanaman utama (tinggi tunggul) (Susilawati et al., 2012b). Namun, belum banyak penelitian yang melaporkan penggunaan bioinsektisida dengan bahan pembawa ekstrak kompos untuk meningkatkan kebugaran padi ratun dan menurunkan populasi dan serangan serangga hamanya. Ekstrak kompos yang merupakan pupuk hayati dapat digunakan sebagai bahan pembawa bioinsektisida cair dengan bahan aktif konidia jamur entomopatogen, seperti Beauveria bassiana (Herlinda et al., 2012). Oleh karena itu, penelitian ini dilakukan dengan tujuan mengkaji pengaruh aplikasi bioinsektisida dan ekstrak kompos terhadap produksi padi ratun dan populasi serangga hama yang menyerang padi ratun tersebut.

\section{BAHAN DAN METODE}

Persiapan Lahan dan Aplikasi Bioinsektisida dan Ekstrak Kompos

Penelitian ini telah dilaksanakan di sentra sawah pasang surut Sumatera Selatan, yaitu Desa Mulia Sari, Kabupaten Banyuasin, sejak Maret hingga Juli 2013. Luas lahan yang digunakan adalah 3 ha dengan sistem budidaya ratun. Metode budidaya padi ratun mengikuti Susilawati et al. (2012b) dengan tinggi pemotongan $20 \mathrm{~cm}$. Varietas padi yang digunakan adalah Inpari 1.

Bioinsektisida cair dibuat berdasarkan metode Herlinda et al. (2012), yaitu menggunakan bahan aktif konidia $B$. bassiana dengan kerapatan $10^{9}$ konidia $\mathrm{mL}^{-1}$ dan bahan pembawanya adalah larutan ektrak kompos yang telah disterilkan pada suhu $100{ }^{\circ} \mathrm{C}$ untuk meniadakan bakteri perombak. Ekstrak kompos pada penelitian ini dibuat mengikuti metode Suwandi (2004), yaitu dengan fermentasi tepung kulit udang. Menurut Suwandi et al. (2012) setiap liter ekstrak kompos tersebut mengandung komunitas bakteri berguna dalam keadaan populasi berimbang, yaitu bakteri perombak kitin (kitinolitik), perombak selulosa (selulolitik) dan pelarut fosfat masing-masing 4.9x108;7.1x108; dan $6.3 \times 108$ sel dalam keadaan dorman (fase istirahat). Bioinsektisida cair yang telah dibuat tadi selanjutnya disemprotkan pada tunggul atau rumpun padi ratun dengan dosis $2 \mathrm{~L} \mathrm{ha}^{-1}$ per aplikasi (perlakuan A), perlakuan lainnya hanya disemprotkan ektrak kompos dengan dosis $2 \mathrm{~L} \mathrm{ha}^{-1}$ per aplikasi (perlakuan B), dan perlakuan terakhir (perlakuan C) dengan cara menyemprotkan kombinasi bioinsektisida dengan dosis $2 \mathrm{~L} \mathrm{ha}^{-1}$ per aplikasi dan ekstrak kompos dengan dosis $2 \mathrm{~L} \mathrm{ha}^{-1}$ per aplikasi. Penyemprotan dilakukan pada sore hari dimulai jam 17.00 WIB untuk melindungi mikroba dari sinar matahari yang membahayakan. Penyemprotan dilakukan saat padi ratun berumur 14, 21, 28, dan 35 hari. Penelitian dirancang dengan menggunakan rancangan kelompok lengkap teracak.

\section{Pengamatan Peubah Agronomi}

Pengamatan peubah pertumbuhan padi ratun dilakukan mulai saat padi ratun berumur 3 (sebelum aplikasi bioinsektisida), 17, 31, 38, 45, 52 hari. Tinggi dan jumlah anakan pada tanaman diamati sesuai dengan sampel rumpun tanaman yang diambil per subpetak yang totalnya 50 rumpun.

Pengamatan peubah produksi padi ratun dilakukan dengan cara setiap petakan lahan dibuat 5 petakan ubin dengan ukuran $2.5 \mathrm{~m}$ x $2.5 \mathrm{~m}$ yang diulang tiga kali sehingga keseluruhan ada 15 ubinan. Tiap petakan ubin diambil 10 sampel rumpun padi sebagai ulangan untuk menghitung berat gabah per rumpun, jumlah bulir per malai, berat gabah per ubinan, jumlah produksi per ha, dan berat gabah per 1,000 bulir, sisanya diambil untuk ditimbang. Rumpun padi yang telah dikeringkan lalu dirontokkan bulirnya. Bulir padi dipisahkan antara yang berisi dan yang hampa. Bulir padi yang berisi dari 10 rumpun sampel ditimbang per rumpun. Lalu digabungkan dengan bulir padi secara keseluruhan per ubin.

\section{Pengamatan Populasi Serangga Hama}

Pengamatan populasi serangga hama dilakukan menggunakan jaring serangga dengan cara ayunan ganda sesuai metode Herlinda et al. (2008a). Jaring diayunkan pada tajuk tanaman padi sebanyak 60 ayunan ganda per subpetak dan dilakukan pada 4 subpetak. Jaring yang digunakan berukuran panjang $100 \mathrm{~cm}$, mulut jaring terbuka dengan diameter $30 \mathrm{~cm}$ dan panjang kantong kain kasa 60 cm (Herlinda et al., 2014). Pengambilan contoh serangga hama ini dilakukan berbarengan dengan pengamatan peubah agronomi, saat padi ratun berumur $3,17,31,38,45,52$ hari umur ratun. Serangga tersebut selanjutnya dibersihkan dari kotoran lainnya, lalu dimasukkan ke dalam botol vial yang berisi alkohol 70\%. Kemudian spesimen yang didapatkan diidentifikasi di Laboratorium Entomologi, Fakultas Pertanian Universitas Sriwijaya, Indralaya.

\section{Analisis Data}

Data peubah agronomi dianalisis secara statistik menggunakan analisis ragam dan diuji lanjut menggunakan BNT 5\%. Data populasi serangga hama dianalisis dengan menggunakan uji Khi Kuadrat pada program quantspy.

\section{HASIL DAN PEMBAHASAN}

\section{Pertumbuhan dan Produksi Padi Ratun}

Hasil analisis ragam menunjukkan tinggi anakan padi ratun yang diberi aplikasi ekstrak kompos paling tinggi dan berbeda nyata dibandingkan petak yang diberi aplikasi bioinsektisida tetapi tidak berbeda nyata dibandingkan petak yang diberi aplikasi kombinasi bioinsektisida dan ekstrak kompos (Tabel 1). Menurut Suwandi et al. (2012) ekstrak kompos tersebut mengandung bakteri perombak kitin (kitinolitik), perombak selulosa (selulolitik), dan 
pelarut fosfat yang mampu meningkatkan serapan $\mathrm{N}, \mathrm{P}$, dan K. Kemampuan ekstrak kompos meningkatkan serapan $\mathrm{N}$ berperan meningkatkan tinggi anakan padi ratun karena menurut Susilawati et al. (2012a) N mampu meningkatkan tinggi tanaman padi ratun. Tingginya unsur $\mathrm{N}$ pada tanah merangsang semakin meningkatnya pembentukan jumlah daun dan batang padi ratun (Islam et al., 2008; Faozi dan Wijornarko, 2010).

Jumlah anakan produktif per rumpun menunjukkan hasil paling tinggi pada petak yang diberi aplikasi ekstrak kompos (14 anakan per rumpun) yang berbeda nyata dengan jumlah anakan pada dua petak lainnya yang diberi aplikasi bioinsektisida ( 8 anakan per rumpun) dan kombinasi bioinsektisida dan ekstrak kompos (5 anakan per rumpun) (Tabel 1). Jumlah anakan produktif pada petak yang diaplikasikan ekstrak kompos adalah paling tinggi. Hal ini merupakan respon umum tanaman padi terhadap aplikasi ekstrak kompos. Rahimi et al. (2011) dan Liu et al. (2012) menyatakan bahwa jumlah anakan padi ratun tidak hanya tergantung pada hara mineral yang diaplikasikan pada ratun tetapi juga ditentukan oleh input $\mathrm{N}$ pada padi utamanya. Suwandi et al. (2012) menambahkan, gejala ini terjadi karena meningkatnya serapan $\mathrm{N}, \mathrm{P}$ dan $\mathrm{K}$ oleh tanaman padi yang diaplikasi ekstrak kompos. Petak yang diberi kombinasi antara bioinsektisida dan ekstrak kompos mempunyai jumlah anakan produktifnya paling rendah. Hal ini disebabkan adanya pengaruh pencampuran mikroba yang berasal dari bioinsektisida dan mikroba yang berasal ekstrak kompos menyebabkan kerja mikrobanya menjadi tidak bersinergis. Fenomena tidak bersinergis mikroba tersebut ditemukan pada penelitian Herlinda et al. (2012) di laboratorium dengan menggunakan serangga uji kutu putih pepaya (Paracoccus marginatus). Petak yang hanya diberi aplikasi bioinsektisida jumlah anakan produktifnya tidak berbeda nyata dibandingkan pada petak aplikasi kombinasi karena pada petak ini ekstrak kompos pada bahan pembawa bioinsektisida tidak mengandung mikroba kitonolitik, selulolitik, dan pelarut fosfat akibat adanya perlakuan sterilisasi suhu $100{ }^{\circ} \mathrm{C}$. Dengan demikian, hasil penelitian ini menunjukkan bahwa ekstrak kompos tunggal yang diaplikasikan pada padi lebih efektif dibandingkan dikombinasikan dengan campuran bioinsektisida.

Berat gabah kering giling, gabah per ubinan atau gabah per hektar, serta berat gabah per 1,000 butir pada petak yang diaplikasikan ekstrak kompos paling tinggi dan berbeda nyata dibandingkan dengan dua perlakuan lainnya (Tabel 2 dan 3). Shrestha et al. (2012) menyatakan cara kerja ekstrak kompos dalam meningkatkan produksi tanaman melalui peningkatan mineralisasi atau melalui ameliorisasi tanah. Liu et al. (2012) menyatakan $\mathrm{N}$ yang diserap padi ratun $57-76 \%$ akan digunakan untuk pembentukan bunga dan dimanfaatkan untuk pembentukan bulir padi ratun. Susilawati et al. (2012a) melaporkan bahwa unsur N mutlak diperlukan dalam menghasilkan ratun yang berproduksi tinggi dan $\mathrm{N}$ dapat dikombinasikan dengan $\mathrm{P}$ atau K. Santoso (2011) menyatakan unsur P dan K secara bersama-sama merangsang pengisian bulir padi, meningkatkan ukuran dan bobot bulir, sehingga dapat meningkatkan hasil gabah dan bulir yang bernas.

\section{Populasi Serangga Hama}

Lahan percobaan dan pada umur ratun 3 hari belum diberi perlakuan bioinsektisida ataupun ekstrak kompos menunjukkan bahwa populasi serangga hama lebih tinggi bila dibandingkan setelah aplikasi saat umur padi mulai 14 hari sehingga saat pengamatan ratun umur 17 hari mulai terjadi penurunan populasi serangga hama (Tabel 4-6). Saat ratun umur 17 hari, populasi Recilia dorsalis dan Ciccadulina bipunctata menurun signifikan setelah

Tabel 1. Pengaruh aplikasi bioinsektida dan ekstrak kompos terhadap tinggi dan jumlah anakan tanaman padi ratun

\begin{tabular}{lcc}
\hline Perlakuan & Tinggi anakan $(\mathrm{cm})$ & Jumlah anakan produktif per rumpun \\
\hline Bioinsektisida & $62.90 \mathrm{a}$ & $8.0 \mathrm{a}$ \\
Ekstrak kompos & $70.40 \mathrm{~b}$ & $14.0 \mathrm{~b}$ \\
Bioinsektisida + ekstrak kompos & $66.10 \mathrm{ab}$ & $5.0 \mathrm{a}$ \\
\hline BNT 5\% & 4.67 & 4.59 \\
\hline
\end{tabular}

Keterangan: Angka yang diikuti huruf yang sama pada kolom yang sama tidak berbeda nyata pada uji BNT 5\%

Tabel 2. Pengaruh aplikasi bioinsektida dan ekstrak kompos terhadap berat gabah kering giling dan jumlah bulir padi ratun

\begin{tabular}{lcc}
\hline Perlakuan & $\begin{array}{c}\text { Bobot gabah kering giling } \\
\text { (g per rumpun) }\end{array}$ & Jumlah bulir per malai \\
\hline Bioinsektisida & $3.00 \mathrm{a}$ & $26.4 \mathrm{a}$ \\
Ekstrak kompos & $7.24 \mathrm{~b}$ & $27.9 \mathrm{a}$ \\
Bioinsektisida + ekstrak kompos & $2.03 \mathrm{a}$ & $26.5 \mathrm{a}$ \\
\hline BNT 5\% & 2.88 & 8.96 \\
\hline
\end{tabular}

Keterangan: Angka yang diikuti huruf yang sama pada kolom yang sama tidak berbeda nyata pada uji BNT 5\% 
Tabel 3. Pengaruh aplikasi bioinsektida dan ekstrak kompos terhadap berat gabah per ubinan dan hektar, serta berat 1,000 bulir padi ratun

\begin{tabular}{lccc}
\hline \multirow{2}{*}{ Perlakuan } & \multicolumn{3}{c}{ Berat gabah } \\
\cline { 2 - 4 } & $\mathrm{g} \mathrm{ubinan}^{-1}$ & $\mathrm{~kg} \mathrm{ha}^{-1}$ & $\mathrm{~g}\left(1,000 \mathrm{bulir}^{-1}\right.$ \\
\hline Bioinsektisida & $214 \mathrm{a}$ & $342.40 \mathrm{a}$ & $21.70 \mathrm{a}$ \\
Ekstrak kompos & $534 \mathrm{~b}$ & $854.00 \mathrm{~b}$ & $24.20 \mathrm{~b}$ \\
Bioinsektisida + ekstrak kompos & $332 \mathrm{ab}$ & $531.20 \mathrm{ab}$ & $22.30 \mathrm{a}$ \\
\hline BNT 5\% & 300 & 480.53 & 1.13 \\
\hline
\end{tabular}

Keterangan: Angka yang diikuti huruf yang sama pada kolom yang sama tidak berbeda nyata pada uji BNT 5\%

diaplikasikan bioinsektisida dan kombinasi bioinsektisida dan ekstrak kompos (Tabel 4). Saat umur ratun 31 dan 38 hari hingga menjelang panen (45 hari) dan setelah panen ratun (52 hari), populasi serangga hama cenderung menurun untuk petak yang diberi aplikasi bioinsektisida atau kombinasi bioinsektisida dan ekstrak kompos (Tabel 5 dan 6). Populasi $R$. dorsalis sebelum aplikasi bioinsektisida sebanyak 30 ekor per 60 ayunan, dan setelah aplikasi hanya 1 ekor per 60 ayunan (Tabel 4). Begitu juga dengan $N$. lugens sebelum aplikasi sebanyak 23 ekor per 60 ayunan, setelah aplikasi bioinsektisida menjadi 2 ekor per 60 ayunan. Sementara kombinasi bioinsektisida dan ekstrak kompos, mampu menurunkan populasi C. bipunctata dari 62 ekor per 60 ayunan menjadi 15 ekor per 60 ayunan (Tabel 4), sedangkan untuk petak yang diberi aplikasi ekstrak kompos cenderung tidak menurunkan populasi serangga hama.

Hasil aplikasi bioinsektisida pada penelitian ini menunjukkan bahwa bioinsektisida mampu menurunkan populasi serangga hama terutama kelompok wereng. Sejalan dengan penelitian Herlinda et al. (2008b) di laboratorium, isolat $B$. bassiana yang belum berbentuk bioinsektisida sudah mampu membunuh lebih dari $90 \%$ wereng coklat, sedangkan walang sangit dapat terbunuh lebih dari $80 \%$ (Herlinda et al., 2008c). Konidia B. bassiana setelah diformulasikan dalam bentuk bioinsektisida menurut Herlinda et al. (2012) dan Nunilahwati et al. (2013) dapat meningkat kemampuan membunuhnya hingga mencapai $100 \%$. Penelitian ini menunjukkan bahwa bioinsektisida yang diaplikasikan pada padi ratun ternyata mampu menurunkan secara siginifikan populasi serangga hama, seperti C. bipunctata, R. dorsalis, N. lugens, dan Nephotettix nigropictus. Herlinda (2010) dan Prayogo (2013) menyatakan serangga hama dapat terbunuh oleh bioinsektisida dari $B$. bassiana dengan cara konidia berkecambah dengan membentuk hifa yang mampu menembus integumen serangga. Selanjutnya pertumbuhan jamur semakin luas terjadi di dalam tubuh serangga hingga menghabiskan cairan tubuh serangga hingga serangga inang mati dan mengering seperti mumi dan proses ini rata-rata terjadi setelah 2 hari pasca infeksi terjadi. Dwiastuti et al. (2007) menambahkan, proses sejak infeksi terjadi hingga inang mati oleh $B$. bassiana ini lebih cepat dibandingkan oleh jamur lainnya, misalnya Metarhizium anisopliae butuh waktu lebih dari 6 hari.

Tabel 4. Pengaruh aplikasi bioinsektida dan ekstrak kompos terhadap terhadap populasi serangga hama padi ratun umur 3 dan 17 hari (ekor/ per 60 ayunan)

\begin{tabular}{|c|c|c|c|c|c|c|}
\hline \multirow[t]{2}{*}{ Spesies serangga hama } & \multicolumn{3}{|c|}{ Umur ratun 3 hari } & \multicolumn{3}{|c|}{$\begin{array}{c}\text { Umur ratun } 17 \text { hari } \\
\text { (3 hari setelah semprot } 1)\end{array}$} \\
\hline & A & $\mathrm{B}$ & $\mathrm{C}$ & A & $\mathrm{B}$ & $\mathrm{C}$ \\
\hline Nilaparvata lugens (Wereng coklat) & 23 & 5 & $19^{*}$ & 2 & 0 & 15 \\
\hline Recilia dorsalis (Wereng zig-zag) & 30 & 13 & $40^{*}$ & 1 & 4 & 34 \\
\hline Nephotettix virescens (Wereng hijau) & 2 & 0 & 8 & 0 & 0 & 8 \\
\hline Nephotettix nigropictus (Wereng hijau) & 10 & 2 & 14 & 7 & 3 & 9 \\
\hline Nephotettix malayamus (Wereng) & 12 & 6 & $15 \mathrm{tn}$ & 1 & 2 & 0 \\
\hline Ciccadulina bipunctata (Wereng) & 64 & 10 & $62 *$ & 28 & 9 & $15^{*}$ \\
\hline Cofana spectra (Wereng putih) & 20 & 6 & $21 *$ & 10 & 11 & $14 \mathrm{tn}$ \\
\hline Leptocorisa acuta (Walang sangit) & 5 & 10 & 4 & 0 & 6 & 2 \\
\hline Cnaphalocrocis medinalis (Hama putih palsu) & 0 & 0 & 0 & 0 & 0 & 0 \\
\hline Chilo suppressalis (Penggerek batang padi bergaris) & 0 & 0 & 0 & 0 & 0 & 0 \\
\hline Total & 166 & 52 & $26^{*}$ & 49 & 35 & $97 \mathrm{tn}$ \\
\hline
\end{tabular}

Keterangan: Angka yang diikuti tanda * pada kolom yang sama berbeda nyata, diikuti tanda tn tidak berbeda nyata pada uji Khi-kuadrat 5\%; A = Bioinsektisida; $\mathrm{B}=$ Ekstrak Kompos; $\mathrm{C}=$ Bioinsektisida + ekstrak kompos 
Bila dikaitkan dengan pengaruh aplikasi bioinsektisida dan ekstrak kompos terhadap pertumbuhan dan produksi padi, ada kecenderungan peubah pertumbuhan dan produksi padi lebih dipengaruhi ekstrak kompos, sedangkan populasi serangga hama lebih dipengaruhi oleh bioinsektisida.
Aplikasi ekstrak kompos signifikan lebih tinggi dalam pertumbuhan dan produksi padi, sedangkan bioinsektisida dapat menurunkan secara signifikasi populasi serangga hama padi ratun.

Tabel 5. Pengaruh aplikasi bioinsektida dan ekstrak kompos terhadap populasi serangga hama padi ratun umur 31 dan 38 hari (ekor per 60 ayunan)

\begin{tabular}{lcccccc}
\hline Spesies serangga hama & \multicolumn{3}{c}{ Umur ratun 31 hari } & \multicolumn{3}{c}{ Umur ratun 38 hari } \\
(3 hari setelah semprot 3) & \multicolumn{2}{c}{ (3 hari setelah semprot 4) } \\
\hline Nilaparvata lugens (Wereng coklat) & A & B & C & A & B & C \\
Recilia dorsalis (Wereng zig-zag) & 2 & 0 & 0 & 4 & 9 & 5 \\
Nephotettix virescens (Wereng hijau) & 0 & 0 & 0 & 5 & 9 & 2 \\
Nephotettix nigropictus (Wereng hijau) & 0 & 0 & 0 & 6 & 13 & 2 \\
Nephotettix malayamus (Wereng) & 10 & 6 & $8^{*}$ & 4 & 6 & 2 \\
Ciccadulina bipunctata (Wereng) & 0 & 0 & 0 & 0 & 6 & 0 \\
Cofana spectra (Wereng putih) & 10 & 7 & $6^{*}$ & 13 & 13 & $10 \operatorname{tn}$ \\
Leptocorisa acuta (Walang sangit) & 15 & 10 & $11^{*}$ & 15 & 8 & $15 \operatorname{tn}$ \\
Cnaphalocrocis medinalis (Hama putih palsu) & 0 & 0 & 0 & 2 & 3 & 6 \\
Chilo suppressalis (Penggerek batang padi bergaris) & 0 & 0 & 0 & 0 & 0 & 4 \\
Total & 0 & 0 & 0 & 0 & 0 & 1 \\
\hline
\end{tabular}

Keterangan: Angka yang diikuti tanda * pada kolom yang sama berbeda nyata, diikuti tanda tn tidak berbeda nyata pada uji Khi-kuadrat 5\%; A = Bioinsektisida; $\mathrm{B}=$ Ekstrak kompos; $\mathrm{C}=$ Bioinsektisida + Ekstrak kompos

Tabel 6. Pengaruh aplikasi bioinsektida dan ekstrak kompos terhadap populasi serangga hama padi ratun umur 45 dan 52 hari (ekor per 60 ayunan)

\begin{tabular}{lllllll}
\hline Spesies serangga hama & \multicolumn{3}{l}{ Umur ratun 45 hari } & \multicolumn{3}{l}{ Umur ratun 52 hari } \\
\hline Nilaparvata lugens (Wereng coklat) & A & B & C & A & B & C \\
Recilia dorsalis (Wereng zig-zag) & 8 & 9 & 5 & 11 & 4 & 6 \\
Nephotettix virescens (Wereng hijau) & 13 & 12 & 1 & 6 & 6 & 5 tn \\
Nephotettix nigropictus (Wereng hijau) & 5 & 13 & 4 & 2 & 2 & 5 \\
Nephotettix malayamus (Wereng) & 6 & 0 & 6 & 4 & 5 & 8 \\
Ciccadulina bipunctata (Wereng) & 2 & 0 & 0 & 1 & 0 & 2 \\
Cofana spectra (Wereng putih) & 2 & 0 & 0 & 3 & 0 & 0 \\
Leptocorisa acuta (Walang sangit) & 3 & 0 & 0 & 3 & 7 & 6 \\
Cnaphalocrocis medinalis (Hama putih palsu) & 0 & 6 & 8 & 0 & 0 & 0 \\
Chilo suppressalis (Penggerek batang padi bergaris) & 0 & 0 & 0 & 0 & 0 & 0 \\
\hline Total & 39 & 0 & 0 & 0 & 0 & 0 \\
\hline
\end{tabular}

Keterangan: Angka yang diikuti tanda * pada kolom yang sama berbeda nyata, diikuti tanda tn tidak berbeda nyata pada uji Khi-kuadrat 5\%; A = Bioinsektisida; $\mathrm{B}=$ Ekstrak kompos; $\mathrm{C}=$ Bioinsektisida + ekstrak kompos

\section{KESIMPULAN}

Perlakuan ekstrak kompos dan kombinasi bioinsektisida dan ekstrak kompos dapat meningkatkan tinggi anakan padi ratun dibandingkan perlakuan bioinsektisida saja. Jumlah anakan produktif per rumpun menunjukkan hasil paling tinggi pada petak yang diaplikasikan ekstrak kompos yang berbeda nyata dengan jumlah anakan pada yang diberi bioinsektisida dan kombinasi bioinsektisida dan ekstrak kompos. Produksi gabah kering giling pada 
petak yang diaplikasikan ekstrak kompos paling tinggi dan berbeda nyata dibandingkan dengan dua perlakuan lainnya. Bioinsektisida yang diaplikasikan pada padi ratun mampu menurunkan populasi serangga hama, C. bipunctata, $R$. dorsalis, $N$. lugens, dan Nephotettix nigropictus. Data ini memberi indikasi bahwa aplikasi ekstrak kompos meningkatkan pertumbuhan dan produksi padi, sedangkan bioinsektisida menurunkan populasi serangga hama padi ratun.

\section{UCAPAN TERIMA KASIH}

Penelitian ini bagian dari Penelitian Hibah Kompetensi yang dibiayai oleh Direktorat Jenderal Pendidikan Tinggi, Kementerian Pendidikan dan Kebudayaan, sesuai dengan Surat Perjanjian Penugasan dalam Rangka Pelaksanaan Program Penelitian Hibah Kompetensi Tahun Anggaran 2013, Nomor: 093.a/UN9.3.1/PL/2013, tanggal 13 Mei 2013 yang diketuai oleh Siti Herlinda.

\section{DAFTAR PUSTAKA}

Dwiastuti, M.E., W. Nawir, dan S. Wuryantini. 2007. Uji Patogenisitas Jamur Entomopatogen Hirsutella citriformis, Beauveria bassiana, dan Metarhizium anisopliae secara Eka dan Dwiinfeksi untuk Mengendalikan Diaphorina Citri Kuw. J. Hort. 17(1):75-80,

Faozi, K., B.R. Wijornarko. 2010. Tanggap tanaman padi sawah dari berbagai umur bibit terhadap pemupukan nitrogen. Agronomika 10:32-42.

Herlinda, S. 2010. Spore density and viability of entomopathogenic fungal isolates from Indonesia, and its virulence against Aphis gossypii Glover Homoptera: Aphididae. Trop.LifeSci. Res. 21:13-21.

Herlinda, S., Waluyo, S.P. Estuningsih, C. Irsan. 2008a. Perbandingan keanekaragaman spesies dan kelimpahan arthropoda predator penghuni tanah di sawah lebak yang diaplikasi dan tanpa aplikasi insektisida. J. Entomol. Indonesia 5:96-107.

Herlinda, S., S.I. Mulyati, Suwandi. 2008b. Jamur entomopatogen untuk mengendalikan wereng coklat pada tanaman padi. Agritrop 27:119-126.

Herlinda, S., S.I. Mulyati, Suwandi. 2008c. Selection of isolates of entomopathogenic fungi, and the bioefficacy of their liquid production against Leptocorisa oratorius Fabricius nymphs. Microbiol. Indonesia 2:141-145.
Herlinda, S., K.A. Darmawan, Firmansyah, T. Adam, C. Irsan, R. Thalib. 2012. Bioesai bioinsektisida Beauveria bassiana dari Sumatera Selatan terhadap kutu putih pepaya (Paracoccus marginatus). J. Entomol. Indonesia 9:81-87.

Herlinda, S., H.C.N. Manalu, R.F. Aldina, Suwandi, A. Wijaya, Khodijah, D. Meidalima. 2014. Kelimpahan dan keanekaragaman spesies laba-laba predator hama padi ratun di sawah pasang surut. J. HPT Tropika $14: 1-7$.

Islam, M.S., M. Hasannuzzaman, M. Rukonuzzaman. 2008. Ratoon rice response to different fertilizer doses in irrigated condition. Agric.Conspect.Sci. 73:197-202.

Liu, K., J. Qin, B. Zhang, Y. Zhao. 2012. Physiological traits, yields and nitrogen translocation of ratoon rice in response to different cultivations and planting periods. Afr. J. Agric. Res. 7:2539-2545.

Nunilahwati, H., S. Herlinda, C. Irsan, Y. Pujiastuti, Khodijah, D. Meidalima. 2013. Uji efikasi bioinsektisida jamur entomopatogen berfomulasi cair terhadap Plutella xylostella (L) di laboratorium. J.HPT Trop.13:52-60.

Oad, F.C., P.S. Cruz. 2002. Rice varietal screening for ratoon ability. Pakistan J. Appl. Sci. 2:114-119.

Prayogo, Y. 2013. Patogenisitas cendawan entomopatogen Beauveria bassiana (Deuteromycotina: Hyphomycetes) pada berbagai stadia kepik hijau (Nezara Viridula L.). J. HPT Tropika 13:75-86.

Rahimi, P.E., N. Ghorban M.M. Javad M. Hamid, M.H. Reza. 2011. Effects of nitrogen fertilization and rice harvest height on agronomic yield indices of ratoon rice-berseem clover intercropping system. Aust. J. Crop Sci. 5:566-574.

Santos, A.B., N.K. Fageria, A.S. Prabu. 2003. Rice rationing management practices for higher yields. Comm.Soil Sci. Plant Anal. 34:881-918.

Santoso, R.S. 2011. Hasil padi sawah yang diaplikasi pupuk organik. J. Agrivigor 10: 319-330.

Shrestha, K., K.B. Walsh, D.J. Midmore. 2012. Microbially enhanced compost extract: Does it increase solubilisation of minerals and mineralisation of organic matter and thus improve plant nutrition? J. Bioremed. Biodegrad. 3:1-9. 
Susilawati, B.S. Purwoko, H. Aswidinnoor, E. Santosa. 2010. Keragaan varietas dan galur padi tipe baru Indonesia dalam sistem ratun. J. Agron. Indonesia 38: $177-184$.

Susilawati, B.S. Purwoko, H. Aswidinnoor, E. Santosa 2012a. Peran hara N, P dan K pada pertumbuhan dan perkembangan ratun lima genotipe padi. J. Agron. Indonesia 40:174-179.

Susilawati, B.S. Purwoko, H. Aswidinnoor, E. Santosa. 2012b. Tingkat produksi ratun berdasarkan tinggi pemotongan batang padi sawah saat panen. J. Agron. Indonesia 40:1-7.

Suwandi. 2004. Effectiveness of shrimps shell compost extract for suppression of leaf diseases on cowpea, chili pepper and cabbage. Pest Trop. J. 1:18-25.

Suwandi, M. Ammar, C. Irsan. 2012. Aplikasi Ekstrak kompos meningkatkan hasil dan menekan penyakit padi sistem ratun di sawah pasang surut Kabupaten Banyuasin. J. Lahan Suboptimal 1:116-122. 